Eur J Clin Chem Clin Biochem

1995; 33:139-145

(C) 1995 Walter de Gruyter \& Co.

Berlin - New York

\title{
(Apo)lipoprotein(a) Concentrations at Birth and in the First Days and Months of Life - Studies on the Distribution of Serum Levels and the Predictive Value of Measurements Made at this Time
}

By William Graham Wood ${ }^{1}$, Marianne Schumacher ${ }^{1}$ and Siegfried Weigert ${ }^{2}$

1 Institut für Klinische Laboratoriumsdiagnostik

${ }^{2}$ Klinik für Kinder- und Jugendmedizin

Klinikum der Hansestadt Stralsund, Stralsund, Germany

(Received October 24, 1994/January 20, 1995)

Summary: This study was carried out on 625 newborns delivered between July 1993 and December 1994 and 221 children visiting the clinic in the first year of life using an immunoluminometric assay specific for apolipoprotein(a), but calibrated with lipoprotein(a), hence the use of the term (apo)lipoprotein(a) for neonatal values. (Apo)lipoprotein(a) concentrations were measured in 278 neonates over the first 12 days of life (median observation time 6 days). A further 64 children were followed up over a period of 1-10 months (median observation time 5 months).

The median (apo)lipoprotein(a) concentration at birth was $14.7 \mathrm{mg} / 1$ (males 14.6 , females $14.7 \mathrm{mg} / \mathrm{l}$ ). The range of concentrations measured was between 1 and $433 \mathrm{mg} / \mathrm{l}$. The correlation coefficient between maternal and neonatal lipoprotein(a) at birth was 0.509 for 483 data pairs.

The behaviour of serum concentrations of (apo)lipoprotein(a)

- during the first days of life varied greatly and was independent of the birth level. Eighty-four babies showed a decrease, 107 an increase and 87 no change in (apo)lipoprotein(a) levels;

- over the first months of life was more unified with 50 children showing an increase in serum lipoprotein(a), a decrease in 4 cases and no change in 10 cases. In these 64 children the median increase in serum (apo)lipoprotein(a) was from $15.8 \mathrm{mg} / \mathrm{l}$ at birth (range 1 to $364 \mathrm{mg} / \mathrm{l}$ ) to $38.5 \mathrm{mg} / \mathrm{l}$ at 6 months.

The median lipoprotein(a) concentrations in the children under 1 year (median age 6 months) was $37.0 \mathrm{mg} / \mathrm{l}$ (males 37.1 , females $37.0 \mathrm{mg} / \mathrm{l}$ ).

The results showed that it is possible to evaluate the risk of elevated lipoprotein(a) levels by comparing the concentrations at birth, or within the first week of life, and after 6 months. A single measurement at birth was not able to be used as a predictor. In cases where (apo)lipoprotein(a) concentrations rose rapidly in the 10 days after birth, the values at 6 months of age all lay in the the upper quartile of results from children of the same age group.

\section{Introduction}

Although several reports on lipoprotein(a) concentrations at birth have been published $(1-5)$, only a few have followed the course of development of serum concentrations of this analyte over the first weeks and months after birth $(1,4)$. This report covers the time period between birth and the end of the first year of life. The observation period has been split into three parts: from birth over the first 12 days of life and between the first and tenth month of life on single 
children, and from isolated observations over the first 12 months of life.

Observations were made at birth on cord and capillary blood as well as in the serum or plasma of the mother. Comparisons were made on a limited number of samples between the apolipoprotein(a) and lipoprotein(a) concentrations at birth using specific assays designed to measure each analyte.

The aim of the study was to establish reference ranges for (apo)lipoprotein(a) in newborns and small children, to study the changes in serum concentrations over the first 12 months of life and to see whether it is possible during this time to predict whether a child will develop pathologically high levels of lipoprotein(a) in serum.

In addition, data from studies on hospitalised adults and children between the age of 1 and 17 years have been included to support the view that it is possible to predict children at risk within the first six months of life.

\section{Materials and Methods}

Subjects studied and data used

Six-hundred-twenty-five newborns delivered between August 1993 and December 1994 in Stralsund were included in the study. This included over $98 \%$ of all births in the town. In addition 221 children under one year of age of attending the childrens' hospital and who had blood taken for routine testing formed part of the study.

The mothers of 483 newborns formed the basis of the comparison of serum lipoprotein(a) concentrations between mother and child at birth. For the development of lipoprotein(a) concentrations during life, data from 1105 children between the age of 1 and 17 years and 918 adults between the age of 18 and 93 years were used as a basis.

The period of investigation on individuals was concentrated on the perinatal period, the first 12 days of life and the first 10 months of life. A total of 709 individual observations were made on the 278 children in the first 10 days of life and 151 observations in the 64 children during the first 10 months of life.

\section{Methodology}

Apolipoprotein(a) and lipoprotein(a) were measured as previously published in this journal (6) using immunoluminometric assays and a single lot of reagents and standards. The assays used polyclonal antibodies, the solid-phase antibody being specific for apolipoprotein(a) and the liquid phase sandwich antibody for either apolipoprotein B or apolipoprotein(a) respectively. Both serum and plasma could be used as sample.

The assay with both antibodies directed against apolipoprotein(a) was used in all cases except for one small comparison study in which the lipoprotein(a) concentration was also measured in newborns using a liquid phase antibody directed against apolipoprotein B. The standard used was calibrated against lipoprotein(a) (Immuno, Heidelberg, Germany) and contained the apolipoprotein phenotype F/B. The choice of the antibody pair against apolipoprotein(a) was made to exclude any possible effects on the assay due to the maturation of apolipoprotein B synthesis over the first 7 days of life (1).

The term (apo)lipoprotein(a) has been chosen for use in neonates as it has been shown (see results) that assay designed to measure lipoprotein(a), i. e. with a liquid-phase antibody direct against apolipoprotein B, gave lower results than the assay designed to measure the apolipoprotein(a) molecule. After the first month of life, there were no significant differences between values obtained with both assays, so that the results were given in terms of lipoprotein(a) in all groups. This was done to allow for comparison with earlier results, and to a limited extent, with results from other groups who normally express their results in terms of lipoprotein(a), regardless as to whether the liquid-phase antibody is directed against apolipoprotein(a) or apolipoprotein B.

\section{Statistics}

Non-parametric statistics were used throughout, as the distribution of apolipoprotein(a) in serum was highly skewed (mean:median $>2.4$ ). The median was used as point of central tendency, relevant percentiles as distribution markers. Correlations were performed on log-transformed data.

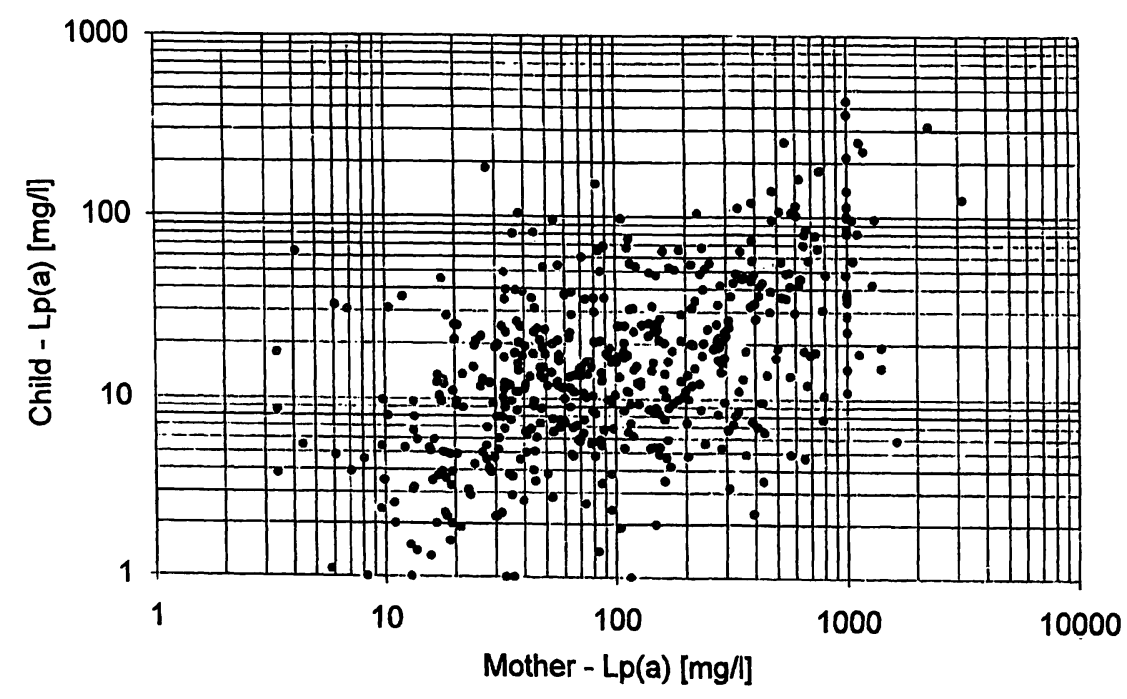

Fig. 1 Scattergram of 483 data pairs showing the relationship between maternal and neonatal lipoprotein(a) concentrations at birth.
The data are correlated with a correlation coefficient of 0.509 . The median maternal lipoprotein(a) value was $101 \mathrm{mg} / \mathrm{l}$, for the neonates $14.9 \mathrm{mg} / \mathrm{l}$. 


\section{Results}

\section{(Apo)lipoprotein(a) concentrations at birth}

The median (apo)lipoprotein(a) concentration at birth was $14.6 \mathrm{mg} / \mathrm{l}$ for boys $(\mathrm{n}=321)$ and $14.7 \mathrm{mg} / 1$ for girls $(n=304)$. The range of concentrations found was between 1 and $433 \mathrm{mg} / \mathrm{l}$. The median age of the mothers was 26 years and their median apolipoprotein(a) concentration was $100 \mathrm{mg} / \mathrm{l}$. The median gestational age was 39 weeks. Figure 1 shows the correlation between maternal and neonatal lipoprotein(a) concentrations in serum and cord blood in 483 cases. The correlation coefficient of 0.509 is in accordance with that expected from an autosomal codominant inheritance. Previous data showed the excellent correlation between cord blood and capillary blood (5). In 105 newborns the correlation coefficient was 0.931 , the regression equation log (capillary blood $)=0.915 \times \log ($ cord blood $)+0.118$ so that either material could be used. Discrepancies were sometimes found where the difference between maternal and neonatal concentrations were extreme (5). There was no correlation between lipoprotein(a) levels and birth weight, a point also noted by Wang et al. (3). Concentrations of lipoprotein(a) were lower, when measured with the assay with the liquid phase antibody directed against apolipoprotein B. In a limited study on 46 samples at birth, the median lipoprotein(a) concentration from the assay using the liquid-phase antibody directed against apolipoprotein(a) was $17.4 \mathrm{mg} / \mathrm{l}$ (range $1.4-67.1 \mathrm{mg} / \mathrm{l}$ ), from the assay using the antibody to apolipoprotein $B$ $13.1 \mathrm{mg} / \mathrm{l}$ (range $1.1-59.3 \mathrm{mg} / \mathrm{l}$ ). Whether or not these differences are of clinical significance or relevance will be seen in a larger prospective study at present being carried out.

\section{Behaviour of (apo)lipoprotein(a) concentrations during the first days of life}

Table la shows the distribution and tendency of (apo)lipoprotein(a) concentrations during the first days (median observation period 6 days, range $2-12$ days) and months (median observation period 6 months, range

Tab. 1a Development of lipoprotein(a) $[\operatorname{Lp}(\mathrm{a})]$ over the first year of life in 342 infants

Development over the first 12 days of life (median observation time -6 days)

\begin{tabular}{rrccccrr}
\hline Lp(a) at birth & $\mathrm{n}$ & Child (1) & Mother & Child (2) & Quotient & Difference & Tendency \\
\hline$<10 \mathrm{mg} / 1$ & 111 & 5.6 & 57.2 & 7.3 & 1.34 & 1.70 & $20-: 51+: 40 \mathrm{nc}$ \\
$10-25 \mathrm{mg} / 1$ & 97 & 15.9 & 102 & 13.7 & 0.92 & -1.40 & $41-: 28+: 28 \mathrm{nc}$ \\
$25-50 \mathrm{mg} / 1$ & 46 & 35.2 & 221 & 32.7 & 0.98 & -0.70 & $17-: 19+: 10 \mathrm{nc}$ \\
$>50 \mathrm{mg} / \mathrm{l}$ & 24 & 79.2 & 500 & 90.2 & 1.02 & 1.60 & $6-: 9+: 9 \mathrm{nc}$ \\
\hline
\end{tabular}

Development over the first 10 months of life (median observation time -6 months)

\begin{tabular}{lllllllll}
\hline $1-364 \mathrm{mg} / 1$ & 64 & 15.8 & 136 & 38.5 & 2.73 & 13.6 & $4-: 50+: 10 \mathrm{nc}$
\end{tabular}

Key to Table:

Child (1) - Lp(a) value at birth $[\mathrm{mg} / \mathrm{l}]$

Child (2) - Lp(a) value on the last day of observation $[\mathrm{mg} / \mathrm{l}]$

Mother - Lp(a) at parturition [mg/l].

All values are median values

\author{
Quotient - Median from all single quotient values \\ [Child (2) / Child (1)]; \\ Difference - Median from all single difference values \\ [Child (2) - Child (1)] [mg/l] \\ Tendency - + denotes increase of more than $20 \%:-$ denotes \\ decrease of more than $20 \%$ : nc denotes no change
}

Tab. 1b Distribution of lipoprotein(a) concentrations (in $\mathrm{mg} / \mathrm{l}$ ) at birth compared with those at a median age of: $(a-d) 6$ days; (e) 6 months (detailed data from table 1a)

\begin{tabular}{|c|c|c|c|c|c|c|c|c|c|c|}
\hline \multirow{2}{*}{$\frac{\text { Groups: }}{\text { Percentile }}$} & \multicolumn{2}{|c|}{ (a) $<10 \mathrm{mg} / 1$} & \multicolumn{2}{|c|}{ (b) $10-25 \mathrm{mg} / 1$} & \multicolumn{2}{|c|}{ (c) $25-50 \mathrm{mg} / \mathrm{l}$} & \multicolumn{2}{|c|}{ (d) $>50 \mathrm{mg} / \mathrm{l}$} & \multicolumn{2}{|c|}{ (e) $1-364 \mathrm{mg} / \mathrm{l}$} \\
\hline & Birth & 6 Days & Birth & 6 Days & Birth & 6 Days & Birth & 6 Days & Birth & 6 Months \\
\hline $2.5\left(5^{*}\right)$ & 1.4 & 1.8 & 10.2 & 3.4 & 25.4 & 8.6 & $52.9 *$ & $23.6 *$ & $2.0^{*}$ & $5.6^{*}$ \\
\hline 16 & 3.5 & 3.9 & 11.1 & 6.8 & 29.5 & 22.8 & 55.6 & 49.5 & 4.1 & 10.4 \\
\hline 50 - Median & 5.6 & 7.3 & 15.9 & 13.7 & 35.3 & 32.7 & 79.2 & 90.2 & 15.8 & 38.5 \\
\hline 84 & 8.4 & 12.4 & 21.1 & 31.4 & 46.5 & 82.7 & 213 & 299 & 54.5 & 170 \\
\hline $97.5\left(95^{*}\right)$ & 9.7 & 51.7 & 24.9 & 75.7 & 49.2 & 153 & $257^{*}$ & $360^{*}$ & $230^{*}$ & $713 *$ \\
\hline
\end{tabular}

* In Groups (d) and (e) the 2.5 and 97.5 percentiles were replaced by the 5th and 95 th percentiles, as the number of data was too small for the former. 


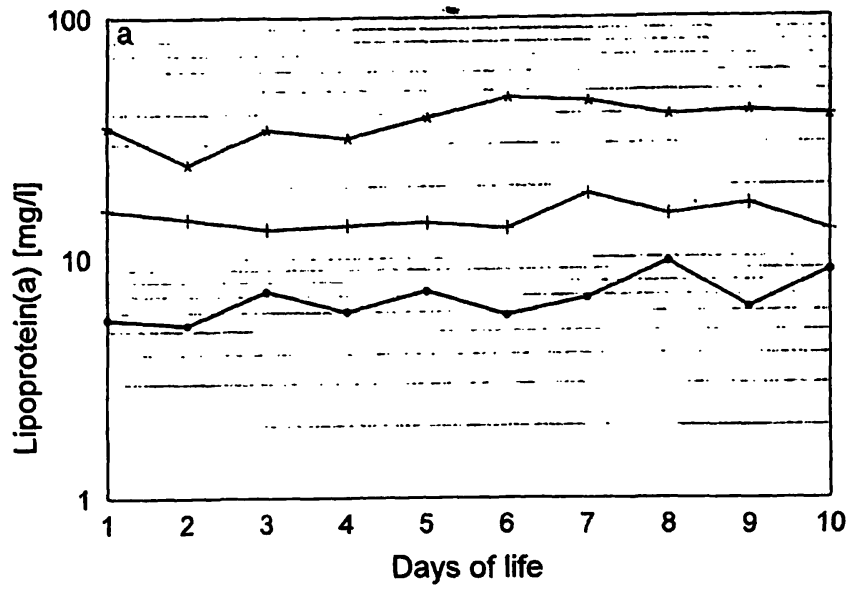

Fig. 2a Median values of lipoprotein(a) concentrations during the first 10 days of life. The groups are defined as in table la. Birth levels $<10 \mathrm{mg} / \mathrm{l}(-\bullet-), 10-25 \mathrm{mg} / \mathrm{l}(-+-), 25-50 \mathrm{mg} / \mathrm{l}$ $(-\star-)$.

1-10 months) of life. The fact that on average, the babies with lower concentrations came from mothers with lower lipoprotein(a) concentrations is also reflected in figure 1 . Table $1 \mathrm{~b}$ shows the distribution of (apo)lipoprotein(a) concentrations at birth and after a median observation period of 6 days in the groups shown in table 1 .

The overall tendency of serum lipoprotein(a) levels over the first days of life was not uniform with increases in 107 cases, decreases in 84 cases and no change in 87 cases. A change was defined as a decrease or increase of over $20 \%$ when compared with the level at birth. The median (apo)lipoprotein(a) concentrations over the first 10 days of life are shown in figure 2a, again using three of the groups from table 1a. Due to insufficient data, the group of neonates with (apo)lipoprotein(a) levels above $50 \mathrm{mg} / \mathrm{l}$ at birth was not included.

Figure $2 \mathrm{~b}$ shows individual cases which typify the development of serum (apo)lipoprotein(a) levels in the early post-natal period.

The cases showing a decline after birth may be associated with the cessation of placental transfer of (apo)lipoprotein(a) from the mother. In all cases where a sharp decrease in concentration was observed, there was a large difference between maternal (high) and neonatal (low) lipoprotein(a) concentrations. This was however not always the case, as many mothers with high lipoprotein(a) levels gave birth to babies with low (apo)lipoprotein(a), but whose levels remained constant or rose after birth, so that placental transfer may only occur in certain cases.

The quotient between last observation and birth (apo)lipoprotein(a) concentrations showed a median change in concentration between -8 and $+34 \%$, representing an

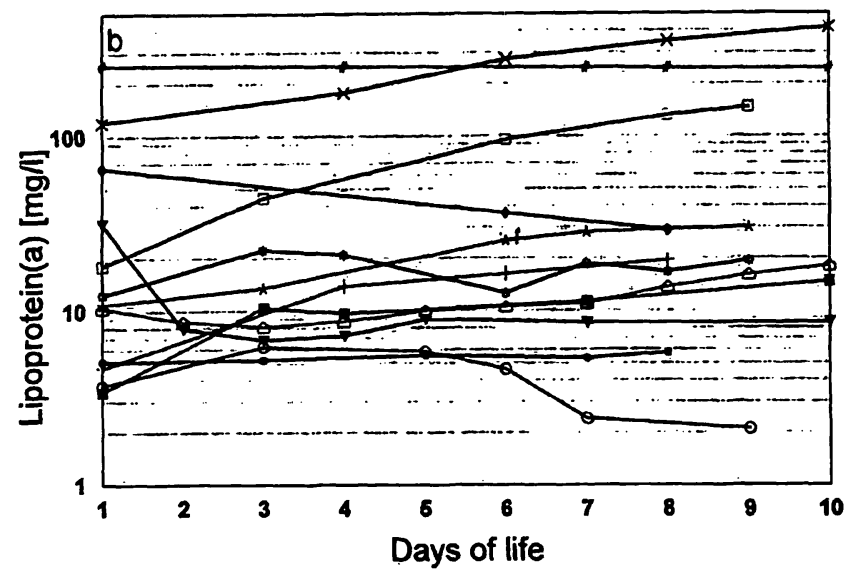

Fig. 2b The trend of lipoprotein(a) concentrations during the week after birth is shown for 12 cases selected to show all possible trends seen within the first 10 days of life.

absolute median concentration change between -1.4 and $+1.7 \mathrm{mg} / \mathrm{l}$ (difference column in table $1 \mathrm{a}$ ). The interesting point to note is that the development of (apo)lipoprotein(a) concentrations in serum over the first few days of life was virtually independent of the birth levels as seen in figure $2 a$, although the spectacular increase were more often noted in the groups with concentrations above $25 \mathrm{mg} / \mathrm{l}$ at birth, as can be seen in the change in distribution of concentrations in table $1 \mathrm{~b}$ and the trends for individual babies in figure $2 b$.

\section{Development of lipoprotein(a) concentrations during the first months of life}

Table 1a also shows the results from 64 newborns who were followed up over the first months of life. The re-

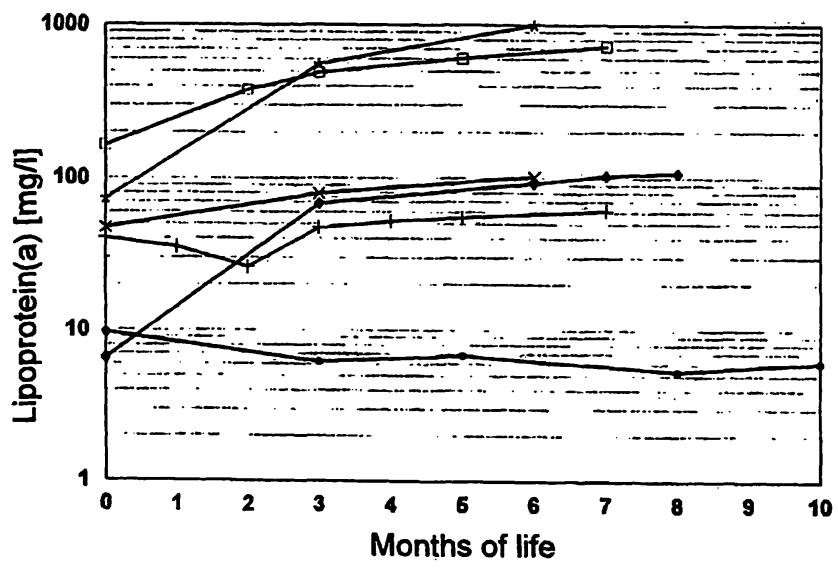

Fig. 3 As for figure 2b, but showing the trend in serum lipoprotein(a) over the first 9 months of life for six selected cases. The parental values in each case were:

Case $1(-\bullet-)$ mother $206 \mathrm{mg} / \mathrm{l}$,

Case $2(-+-)$ mother $239 \mathrm{mg} / \mathrm{l}$,

Case $3(-\star-)$ mother $1110 \mathrm{mg} / \mathrm{l}$,

Case $4(-\square-)$ mother $625 \mathrm{mg} / \mathrm{l}$,

Case $5(-x-)$ mother $395 \mathrm{mg} / \mathrm{l}$,

Case $6(--) \quad$ mother $40.4 \mathrm{mg} /$, father $52 \mathrm{mg} /$; father not measured; father $526 \mathrm{mg} / \mathrm{l}$; father $420 \mathrm{mg} / \mathrm{l}$ : father not measured; father $102 \mathrm{mg} / \mathrm{l}$. 


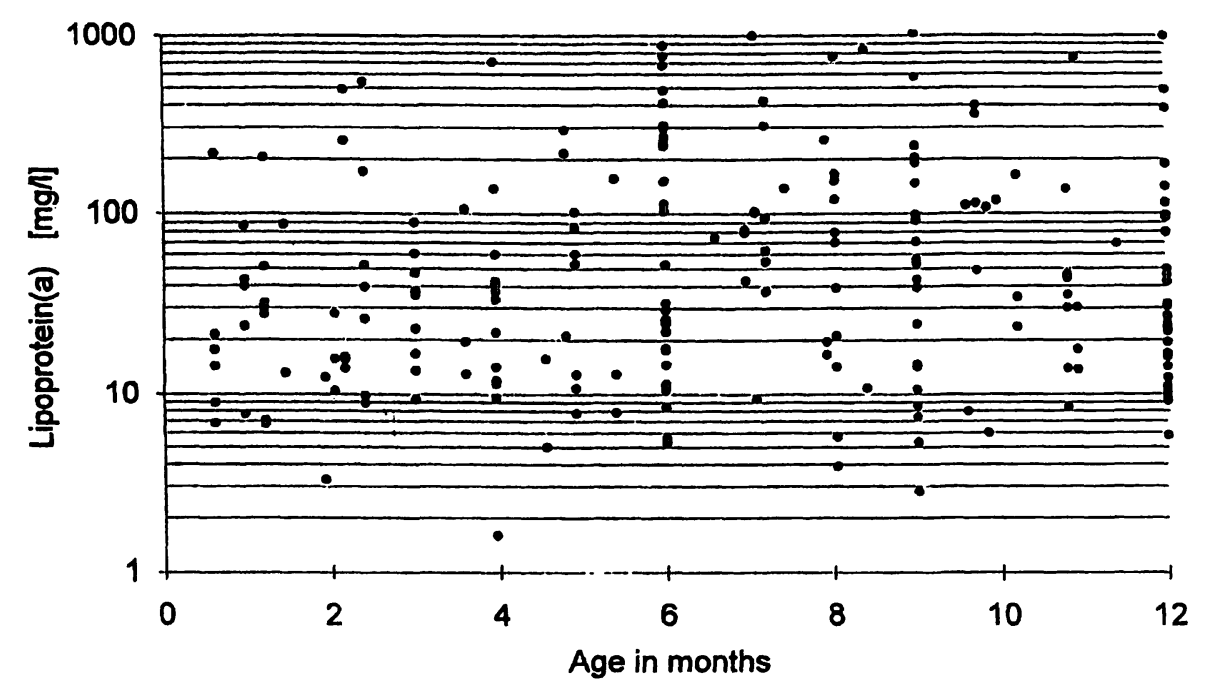

Fig. 4 Scattergram showing lipoprotein(a) concentrations in young children between the ages of 2 weeks and 1 year. Samples came from children who were admitted to hospital during the first year of life. The children had no known lipid disorder at the time of admission. sults were either obtained from babies attending the clinic for diverse reasons, or from routine check-ups between 5 and 7 months of age. None of the children was known to have a lipid disorder at the time.

The results here are more uniform with 50 children showing an increase in serum lipoprotein(a), 4 a decrease and no change in a further 10 cases. The median increase seen was. from 16.8 to $37.4 \mathrm{mg} / 1$ representing a median percentage change of $144 \%$. Figure 3 shows 6 individual cases.

Results from a further 221 children who attended the childrens' hospital during the first year of life serve as a control for the general development of lipoprotein(a) levels and are shown as a scattergram in figure 4 . The median levels of lipoprotein(a) in serum in both the 64 children who were individually followed up and the 221 children who had a single determination were comparable with $38.5 \mathrm{mg} / \mathrm{l}$ and $37.0 \mathrm{mg} / 1$ respectively, showing that the samples were most probably taken from populations with the same characteristics, thus allowing comparisons to be made.

\section{Additional data used for comparative and extrapolative purposes}

Figure 5a shows the distribution of lipoprotein(a) values in different age groups up to the age of 30 years of age, figure $5 \mathrm{~b}$ showing the median concentrations for the same groups according to sex, and including individuals up to 93 years of age. With these data it is possible to estimate the adult levels of lipoprotein(a) and assess the additional risk of early onset of atherosclerotic disease by extrapolation. It can be seen from figure 5a that serum lipoprotein(a) concentrations of $1000 \mathrm{mg} / \mathrm{l}$ occur during the first year of life and that values exceeding $2500 \mathrm{mg} / \mathrm{l}$ can be measured in children under 5 years of age. Between the ages of 6 and 30, the 84th percentile changes from 341 to $397 \mathrm{mg} / \mathrm{l}$, the 95 th percentile from 712 to $957 \mathrm{mg} / \mathrm{l}$ and the 99th percentile from 1234 to $1286 \mathrm{mg} / \mathrm{l}$. Even at the age of 6 years, over $20 \%$ of all children had lipoprotein(a) values above $300 \mathrm{mg} / \mathrm{l}$. The median values in figure $5 \mathrm{~b}$ an increase in lipoprotein(a) concentrations over the first 5 years of life, with more or less constant median concentrations between 6 and 30 years of age. In addition, a bimodal distribution was seen for hospitalised males with peaks around 40 and 65 years, hospitalised females having a single postmenopausal peak.

\section{Discussion}

This study has concentrated upon the development of (apo)lipoprotein(a) levels during the first days and months of life in order to see how soon it is possible to

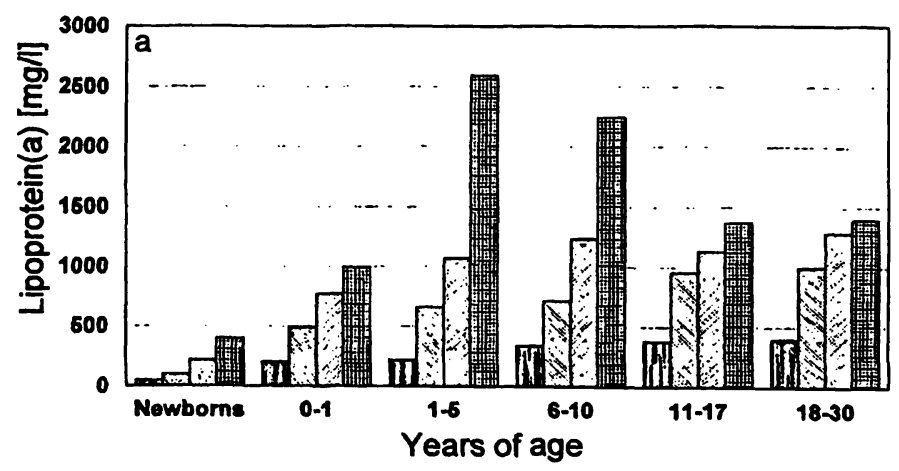

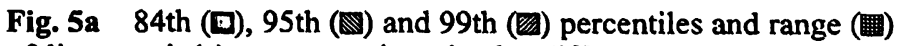
of lipoprotein(a) concentrations in the different age groups from birth to 30 years of age. 


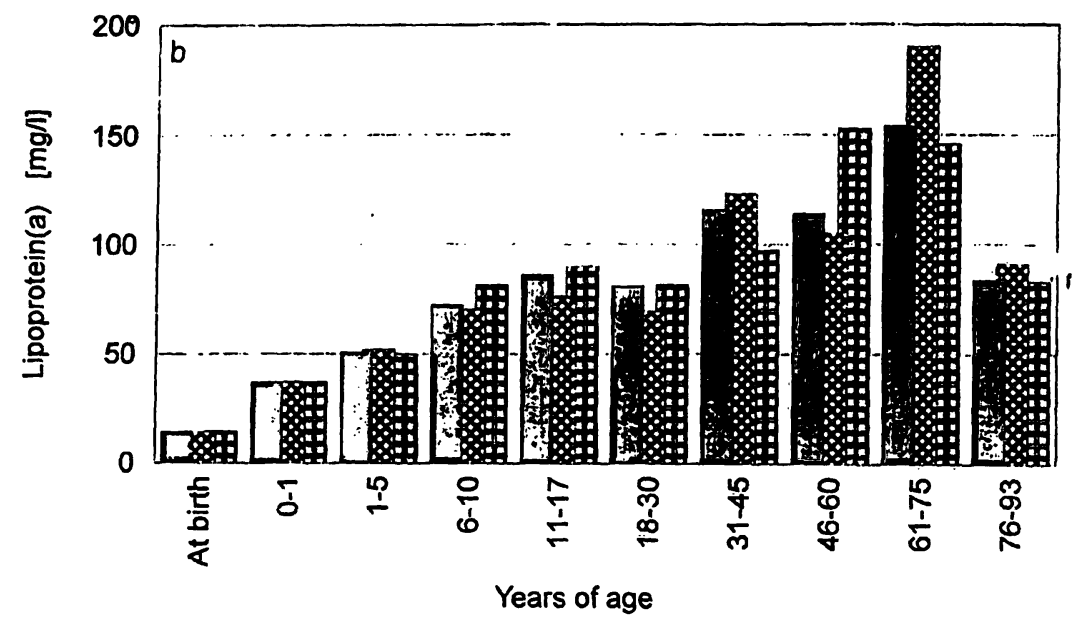

Fig. 5b Median lipoprotein(a) concentrations in 2700 hospitalised individuals (1297 males, 1403 females) according to age and sex. The results show peaks which correspond to the age groups with the highest incidence of coronary heart disease, i. e. men between
30 and 45 years of age, and between 60 and 75 years of age, and women after the menopause between 55 and 65 years of age. The

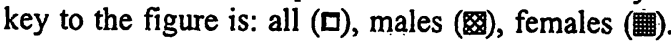

predict whether a child has an additional risk factor, namely that due to elevated lipoprotein(a) concentrations in serum. The results of this study do not agree fully with those of van Biervliet and co-workers (1) who reported a significant rise in lipoprotein(a) concentrations during the first week after birth, together with a continual increase up to 180 days post partum. The discrepancy in the lipoprotein(a) concentrations may have been method dependent as the assay used in the present study used two antibodies directed against apolipoprotein(a). Van Biervliet described an increase of apolipoprotein B synthesis, which plateaus after around 7 days, a point which may influence the measured concentrations of lipoprotein(a) using an assay with one antibody directed against apolipoprotein B. In theory there is sufficient apolipoprotein B present in neonatal serum to allow for the combination with apolipoprotein(a) to give intact lipoprotein(a). The results presented here using the sandwich assay with an anti-apolipoprotein B antibody gave slightly lower results at birth and during the first 10 days of life than the assay using two antibodies directed against apolipoprotein(a), which suggests that there is free apolipoprotein(a) in neonatal serum at birth. As seen in figure $2 \mathrm{a}$, there is no net change of apolipoprotein concentrations in the 10 days following birth, although individual values may change greatly as seen in figure $2 b$. Previous results from the present authors (5) have shown that after the perinatal period there is no difference in the results from assays designed to measure apolipoprotein(a) and those for lipoprotein(a).

The original idea that it may be possible to detect children who will develop high levels of lipoprotein(a) already at birth by measuring (apo)lipoprotein(a) in cord blood proved to be negative. The changes over the first week of life only allowed a prediction of a value lying in the risk range in less than $10 \%$ of all cases studied, these being typified in figure $2 \mathrm{~b}$. The recommendations of van Biervliet et al. (2), of setting a cut-off value of $1000 \mathrm{mg} / \mathrm{l}$ for infants at risk using an enzyme immunoassay in blood spots to measure lipoprotein(a) in $\overrightarrow{5}-7$ day old infants, cannot be accepted on the basis of the results reported in this article. The results from Wilcken et al. (4) showed apolipoprotein(a) serum values corresponding to a median level of lipoprotein(a) of $30 \mathrm{mg} / 1$ and a 95th percentile value of $130 \mathrm{mg} / \mathrm{l}$ at an range of 3-5 days, concentrations higher than those found in the present study, namely 14.8 and $101 \mathrm{mg} / \mathrm{l}$ respectively. The differences may be explainable in the standardisation of the assays used.

The results from Wilcken and coworkers (4) showed a good correlation between apolipoprotein(a) concentrations at birth and after 8.5 months with a twofold increase in concentration. The present study, although not confirming the good correlation, also showed a median increase of $144 \%$ over a six month period.

The correlation between mother and child at birth was similar to that found by Wilckens et al. (4), these authors finding a correlation coefficient of 0.521 in 51 cases measured at 8.5 months, the present study a correlation coefficient of 0.509 for 483 cases measured at birth.

By combining the value at birth with that at around 6 months of age it appears to be possible to predict with a good degree of accuracy, whether a child is at risk or not. The accurate determination and documentation of (apo)lipoprotein(a) at birth is a prerequisite, and calls for a specific method able to measure concentrations under 10 , better under $5 \mathrm{mg} / \mathrm{l}$. This rules out the relatively unspecific nephelometric/turbidimetric methods as well 
as rocket electrophoresis and many immunoassays with insufficient analytical lower detection limits.

A second measurement of neonatal serum lipoprotein(a) within the first days of life can serve to eliminate falsely high concentrations due to maternal contamination of cord blood. This value can also act to stabilise the baseline measurement. An ideal time for confirmative/alternative sampling is when blood is taken for phenylketonuria and connatal hypothyroidism. Two measurements are needed for predictive purposes, one within the first week of life and a second around 6 months of age.

The determination of lipoprotein(a) as in this study can only be seen as one link, even if this is an important one, in the diagnostic chain. Recent results from Sorensen et al. (7) however tend to support the importance of lipoprotein(a) as an independent risk factor, as this group found that the early changes in vessel wall elasticity in children with inherited hypercholesterolaemia only correlated with serum lipoprotein(a) levels. The aim of the authors is to apply these findings in a reverse way, namely to check if elevated serum lipoprotein(a) levels in children correlate with an increase in pulse-wave velocity using a non-invasive technique of rheography or Doppler sonography. Early changes in vessel-wall

\section{References}

1. Van Biervliet JP, Labeur C, Michiels G, Usher DC, Rosseneu M. Lipoprotein(a) profiles and evolution in newborns. Atherosclerosis $1991 ; 86: 176-81$.

2. Van Biervliet JP, Michiels G, Rosseau M. Quantification of lipoprotein(a) in dried blood spots and screening for abovenormal lipoprotein(a) concentration in newborns. Clin Chem 1991; 37:706-8.

3. Wang XL, Wilcken DE, Dudman NP. Neonatal apo A-I, apo$\mathrm{B}$ and apo(a) levels in dried blood spots in an Australian population. Pediatr Res 1990; 28:496-501.

4. Wilcken DE, Wang XI, Dudman NP. The relationship between infant and parent Lp(a) levels. Chem Phys Lipids 1994; 67/ 68:299-304.

5. Schumacher $M$, Keßler A, Meier A, Weigert S, Wood WG. Lipoprotein(a) concentrations in cord and capillary blood from newborns and in serum from in-patient children, adolescents and adults. Eur J Clin Chem Clin Biochem 1994; 32:341-7.

6. Keßler A, Schumacher M, Wood WG. Immunoluminometric assays for the quantification of apolipoproteins A-I, B, C-II, elasticity have already been documented for diabetic children using Doppler sonography to measure pulsewave velocity (8).

Even though there is no medication at present available for correction of elevated levels of serum lipoprotein(a), the screening of young children can lead to a register of children at risk, so that these can be included in a therapy scheme, as soon as one becomes available, as well as in an education project where other potential risk factors can be minimised.

The data from hospitalised children and adults was included not only to be able to predict the children at risk, but to show that the peaks in the median lipoprotein(a) concentration in hospitalised adults correspond with those age groups with the highest risk of coronary heart disease and myocardial infarct. These results support the role of lipoprotein(a) as an independent risk factor for the development of atherosclerotic disease.

\section{Acknowledgements}

The technical assistance of Frau Christa Bolte is gratefully acknowledged in the routine determination of lipoprotein(a), as is the help and co-operation of the staff of the delivery room and neonatal wards of the hospital for the collection of blood samples at birth, and the staff of the childrens' wards from the children studied. (a) and lipoprotein(a). Eur J Clin Chem Clin Biochem 1994; 32:127-35.

7. Sorensen KE, Celermajer DS, Georgakopoulos D, Hatcher G, Betteridge DJ, Deanfield JE. Impairment of endothelium-dependent dilation is an early event in children with familial hypercholesterolemia and is related to the lipoprotein(a) level. J Clin Invest 1994; 93:50-5.

8. Krause M, Ederer G, Regling B, Holker S, Bartels H. Früherkennung von Veränderungen peripherer Gefäße bei Kindern und Jugendlichen mit insulinpflichtigem Diabetes mellitus durch Doppler-Ultraschall. Monatsschr Kinderheilkd 1991; 139:282-6.

Prof. Dr. W. G. Wood

Institut für Klinische Laboratoriumsdiagnostik

Klinikum der Hansestadt Stralsund

Krankenhaus am Sund

Postfach 103

D-18402 Stralsund

Germany 


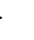

$-4$ 